\title{
Thinking about the Past: Early Knowledge about Links between Prior Experience, Thinking, and Emotion
}

\author{
Kristin Hansen Lagattuta and Henry M. Wellman
}

\begin{abstract}
In two studies the authors investigated the situations where 3- to 7-year-olds and adults $(N=152)$ will connect a person's current feelings to the past, especially to thinking or being reminded about a prior experience. Study 1 presented stories featuring a target character who felt sad, mad, or happy after an event in the past and who many days later felt that same negative or positive emotion upon seeing a cue related to the prior incident. For some story endings, the character's emotion upon seeing the cue matched, or was congruent, with the current situation, whereas for others, the emotion mismatched the present circumstances. Participants were asked to explain the cause of each character's current feelings. As a further comparison, children and adults listened to behavior cuing stories and provided explanations for characters' present actions. Study 2 presented emotional scenarios that varied by emotion-situation fit (whether the character's emotion matched the current situation), person-person fit (whether the character's emotion matched another person's), and past history information (whether information about the character's past was known). Results showed that although there were several significant developments with increasing age, even most 3-year-olds demonstrated some knowledge about connections between past events and present emotions and between thinking and feeling. Indeed, children 5 years and younger revealed strikingly cogent understanding about historical-mental influences in certain situations, especially where they had to explain why a person, who had experienced a negative event in the past, was currently feeling sad or mad in a positive situation. These findings help underwrite a more general account of the development of children's coherent understandings of life history, mind, and emotion.
\end{abstract}

\section{INTRODUCTION}

Humans are social creatures, spending the majority of our lives talking with, interacting with, and thinking about other people. Emotions are powerful regulators and organizers of this social enterprise. How we interpret social experiences and express and act upon our own feelings and the feelings of people around us can encourage, maintain, or disrupt social bonds. At the same time, social interactions are critically guided by our knowledge of people's inner mental lives, their minds. We understand people as intentional and goal-directed, and thus, we interpret actions and emotions with respect to what a person (or what we think a person) wants, believes, thinks, or intends. Underpinning this mental-psychological stance toward persons is a key appreciation of people as historical individuals, as beings living lives extended through time. That is, we understand that people's current actions, emotions, and thoughts are not only shaped by the here and now but are also intimately connected to their experiences from the past.

Although these are often studied as three separate foundations of social knowledge, the current research examines children's development of a coherent understanding of persons-their knowledge about connections between life history, mind, and emotion. Indeed, achieving a naïve psychological understanding of people requires more than just an awareness of a va- riety of states and occurrences (e.g., emotions, thoughts, actions) - children must learn to assemble these notions together to provide coherent, holistic explanations of their own and others' lives.

How might past events, thoughts, and emotions be connected? From an everyday commonsense view, we often find ourselves experiencing emotions that are not caused by present situations per se but rather by the thoughts these events trigger in our minds, including thoughts about past experiences. Thinking about positive experiences can energize or comfort, whereas ruminating on negative images can depress or enrage. This interconnection between thoughts and feelings is stressed in scientific as well as everyday theories. Cognitive theories of depression, for example, emphasize the causative role of thinking, with therapy aimed at changing thought processes to improve emotional well-being (e.g., Abramson, Seligman, \& Teasdale, 1978; Beck, 1976; Nolen-Hoeksema, 1991; Sacco \& Beck, 1985). Importantly, in our everyday social cognition we construe the link between situations, thoughts, and emotions as distinctively individual. That is, because the biographical landscapes of our lives are different, we understand that the same situation can elicit different thoughts and therefore

(C) 2001 by the Society for Research in Child Development, Inc. All rights reserved. 0009-3920/2001/7201-0006 
different emotions in different people. For example, we know that a child whose kitten was lost forever may feel sad upon seeing a cat's collar, whereas for another child the collar may elicit no emotions or even positive ones. We realize that the collar may cause the first but not the second child to remember and dwell upon the tragedy of her lost pet.

The current research investigates the degree to which 3- to 7-year-olds share these same insights about interconnections between past events, thoughts, and emotions. The focus was particularly on developmental changes in two features of children's explanations for people's emotions in different kinds of situations: (1) When do children explain people's feelings as caused by their past experiences rather than by recent events in or their appraisals of current circumstances? And, (2) in what kinds of situations do they explain people's emotions as caused by their thinking about a significant event from the past? As we will show, children's explanations reveal developing insight into two key understandings: that people's emotional reactions to current situations can be shaped by their distinctive experiences from the past, and that thinking can influence a person's emotional well-being.

Recent research by Lagattuta, Wellman, and Flavell (1997) showed that children start to link past experience, current emotion, and thinking during the preschool years. For example, imagine that Anne's favorite doll was stepped on by a circus clown. Many days later she goes to a birthday party, sees the clown perform, and starts to feel sad. Lagattuta et al. (1997) presented preschoolers with stories featuring such cue-to-past-event scenarios and asked them to explain the cause of the current emotions. Many 3-yearolds, the majority of 4-year-olds, and nearly all 5- and 6-year-olds could sometimes explain that a person's emotions were caused by being reminded about the past, termed a cognitive cuing explanation (e.g., "Anne's sad because the clown makes her remember about her broken doll"). By age 5, children used cognitive cuing to explain characters' emotions across the majority of the six story trials. Moreover, preschoolers demonstrated awareness that this link between situations, thoughts, and emotions is individualized. That is, even 3-year-olds consistently predicted that the cue would elicit different emotions in someone who did not share in the past event.

The knowledge preschoolers revealed in this research about connections between thinking, past events, and emotion is at odds with many earlier findings. For example, although several studies have shown that 3- to 6-year-olds know something about how mental states mediate between situations and emotions-people's desires for, beliefs about, or appraisals of an event can influence their emotions (Banerjee, 1993; Harris, Johnson, Hutton, Andrews, \& Cooke, 1989; Wellman \& Banerjee, 1991)—preschoolers' understanding about the process of active, mental ideation, or thinking, has been shown to be limited. Here, it is important to distinguish between two senses of "thinking." In a very broad sense, "thinking" is used to encompass most mental states (e.g., desiring, remembering, perceiving). In a strict sense, however, "thinking" refers only to active, conscious, ongoing mental activity. Thus, despite young children's knowledge about some connections between emotion and thinking construed broadly (e.g., between goals and emotions; see Stein \& Levine, 1987, 1989; Stein \& Trabasso, 1989), they demonstrate only minimal understanding of the presence and influence of thinking in the strict sense (see Flavell, Green, \& Flavell, 1995). For example, unlike older children and adults, preschoolers rarely suggest changing one's appraisal or thoughts about a situation as a means for alleviating negative emotion (Altshuler \& Ruble, 1989; Band \& Weisz, 1988; Harris, 1989; Harris, Guz, Lipian, \& Man-Shu, 1985; Harris \& Lipian, 1989). Moreover, children younger than 8 are not consistently aware of when and what people are thinking about, even persons engaged in mental tasks such as reading, attending effortfully, or problem solving (Flavell, Green, \& Flavell, 1993; Flavell et al., 1995; Flavell, Green, \& Flavell, 1998; but see Estes, 1998).

In contrast, Lagattuta et al.'s (1997) findings demonstrate an early appreciation of the influence of active thinking on emotions (thinking in the narrow sense) combined with an awareness of important connections between emotions, thinking, and prior experience. These data cannot be easily discounted. The results were replicated across three different studies using a variety of cue types and formats. More importantly, children's knowledge about thinking, cognitive cuing, and emotions was not simply inferred from yes/no responses or forced choice answers. Rather, children's explanations confirmed their coherent understandings.

The possibility explored in this study is that young children are indeed knowledgeable about the presence and influence of thinking, even in the narrow sense, and important connections between past events, thoughts, and emotions, but, at first, only in certain limited contexts. Although varied in several fashions, the stories used by Lagattuta et al. (1997) all shared three features: (1) they focused on sadness; (2) they required children to explain emotional reactions that were unusual given the present circumstances (e.g., feeling sad at a birthday party); and (3) they pro- 
vided information about characters' relevant past experiences (e.g., the clown broke the character's doll in the past). Any or all of these features may encourage children to link current emotions to thinking about the past. If influential, these features would provide important insights into the developmental course of a coherent understanding of past history, mind, and emotion.

Consider emotion valence. Natural language research has shown that preschoolers spontaneously talk with their parents more often about the causes of unpleasant emotions than the sources of positive feelings (Dunn, Bretherton, \& Munn, 1987; Dunn \& Brown, 1993; Lagattuta, 1999), and reminisce more frequently about past negative versus past positive experiences (Dunn \& Brown, 1991; Fivush, 1991; Kuebli \& Fivush, 1992; Lagattuta, 1999; Miller \& Sperry, 1988). This focus may encourage children to develop earlier, more sophisticated knowledge about the causes of negative emotions before positive emotions, particularly in relation to a person's prior history. Consistent with this, exploratory data from Gnepp and Gould (1985) revealed that 5- and 8-year-olds could more accurately predict how a past negative versus a past positive experience would change a person's emotional reaction to a current situation. Yet, structured interview studies have found that when young children are asked to describe an emotional event from the past, they provide more lengthy (but not necessarily more causal or evaluative) narratives about "happy" events in comparison with "mad," "sad," or "afraid" episodes (Liwag \& Stein, 1995).

Aside from emotion valence, the degree to which a person's emotion is congruent, or matches the objective situation, may well be influential; this congruence can be referred to as emotion-situation fit. Even young preschoolers can pair conventional emotional reactions to common situations, such as, gifts make a person happy (Borke, 1971; Russell, 1990). When faced with characters displaying atypical emotions (e.g., feeling mad upon receiving a present), young children often reconcile this conflicting information by referring to people's unique attitudes or appraisals (Gnepp, 1983; Gove \& Keating, 1979). In contrast, when a person's feelings are conventional for a situation, such person-specific information is often ignored (Gnepp, 1989; Gnepp, Klayman, \& Trabasso, 1982). Even adults more frequently attribute people's atypical reactions to psychological causes rather than to external events (Jones, 1990; Jones \& Nisbett, 1971; Kelley, 1967, 1971). Reasonably, then, because the scenarios used by Lagattuta et al. (1997) asked children to explain people's sadness that "mismatched" current situations (e.g., Anne feels sad when a clown gives her a balloon), they may have encouraged children to look beyond the "here and now" and consider their past experiences and their thoughts. Indeed, Gnepp (1989a) proposes that young children's search for personal information is often motivated by incongruence between a person's emotion and the situation.

Finally, emotional situations themselves may facilitate children's early knowledge about thinking. For example, in one of their 14 studies, Flavell et al. (1995) found that young children more consistently attributed thoughts to people during emotionally arousing events (e.g., waiting to get a shot) than during physical or cognitive activities (e.g., reading a book). Indeed, 5- and 7-year-olds asserted that people sitting quietly before or after a negative event were thinking nearly $100 \%$ of the time. This differential knowledge about thinking for emotions versus actions suggests that young children's first insights about thinking as conscious, active, mental ideation may be intimately tied to their understanding of emotion, not people's minds in general.

In sum, young children's early knowledge about connections between past events, thinking, and current experience may be especially revealed in emotional versus behavioral contexts, and especially in situations where (1) people are experiencing negative versus positive feelings; (2) people's feelings are unusual in that they cannot easily be explained by current events; and (3) they are provided with information about people's prior related experiences. The present research examines the significance of all three of these factors.

\section{STUDY 1}

The primary focus of Study 1 concerned preschoolers' understanding about connections between past events, thoughts, and current emotions, as influenced by differences in emotion valence (i.e., positive or negative emotional reactions) and differences in emotionsituation fit (i.e., the degree to which the person's emotion is conventional or unusual for the situation).

To investigate whether emotional situations in general promote children's early understanding of thinking, Study 1 further examined whether children would explain people's current feelings as caused by thinking more often than people's current nonemotional behaviors. This emotion versus behavior contrast was chosen to provide a direct test of Flavell et al.'s (1995) suggestive evidence that young children may develop earlier competence in linking thinking and emotions in comparison to thinking and actions. 


\section{Method}

Participants

Seventy-two children and adults participated; eighteen 3-year-olds $(M=3,8$, range $=3,6-3,11)$, eighteen 4-year-olds $(M=4,6$, range $=4,0-4,11)$, eighteen 5-yearolds $(M=5,6$, range $=5,0-6,6)$, and eighteen young adults $(M=20,9$, range $=18,2-27,10)$, with 9 males and 9 females in each age group. All participants were residents of a midwestern university community. Children were recruited from multiple preschool and kindergarten classrooms in the local area, and adults were undergraduate or graduate students at the university. In total, the participants were 77\% European American, 17\% Asian American, and 6\% other ethnicities. To aid in developing appropriate story scenarios, an additional 15 preschoolers participated in pilot testing.

\section{Materials and Procedure}

We designed two types of stories: four emotioncuing stories (two focusing on positive emotions and two focusing on negative emotions) and two behaviorcuing stories. Each story presentation consisted of eight simple colorful pictures on $5 \times 6$ inch laminated cards. Figure 1 shows a pictorial example of a negative emotion-cuing story and Figure 2 illustrates an example of a behavior-cuing story.

As shown in Figure 1, emotion-cuing stories featured a target character who experiences an affective event (happy, sad, mad - in this case sad) paired with a particular visual cue. Many days later, the character sees an identical object from his or her past experience (i.e., the cue) and reexperiences the same emotion. Each emotion-cuing story had two types of endings. In emotion-match endings, the character's emotion after encountering the cue is congruent with the current situation, whereas in emotion-mismatch endings the character's emotion after seeing the cue is atypical for, or discordant with, the current situation.

For example, Figure 1 shows a story about a girl who feels sad when her rabbit is scared away by the neighbor's black-spotted dog. For the emotion-match version, she feels sad many days later when the same spotted dog tramples some flowers she had just picked. Thus her emotion (sad) matches, or is congruent with, the event in the current situation (dog tramples flowers). For the alternative emotion-mismatch version of the same story, the girl feels sad again when the same spotted dog slowly walks over, sits down, and wags his tail "real friendly." Here, her sadness mismatches, or is unusual for, the pleasant current situation (dog wagging tail). The other negative

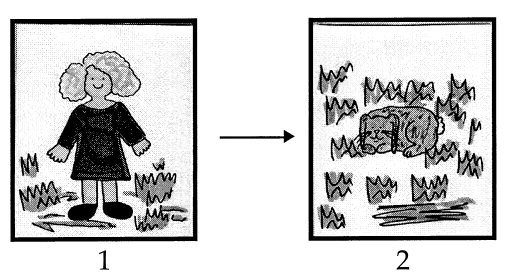

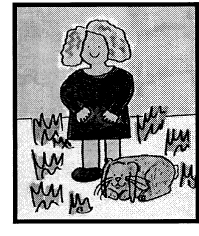

3
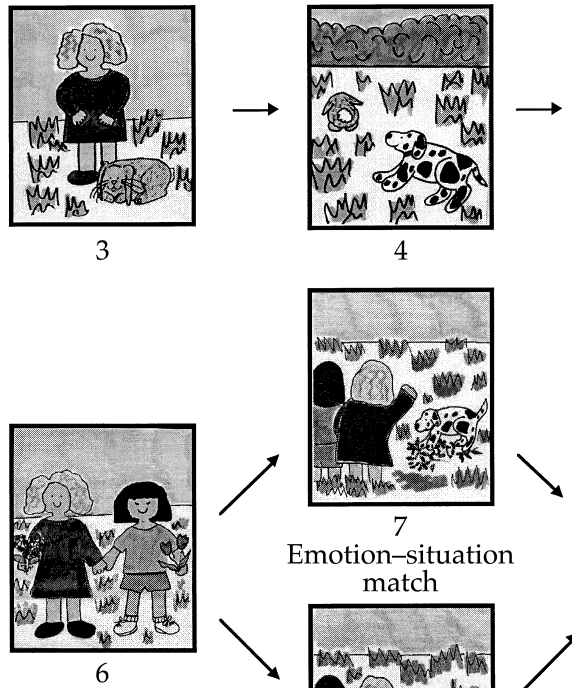

4

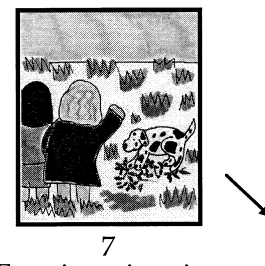

Emotion-situation match

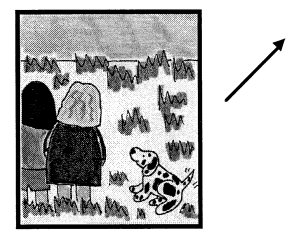

Emotion-situation mismatch

Figure 1 Illustrations for a negative emotion-cuing story used in Study 1 shown in reduced form.

story featured a girl who feels mad when a clown breaks her favorite doll and who later feels mad again at a party when that same clown either (1) gives her a red balloon, or (2) soaks her with a water balloon. One positive story featured a boy who feels happy when his dog performs an "amazing new trick" with a star beanbag. Many days later the boy feels happy again when (1) he reaches to pick up the star beanbag and finds a shiny quarter or (2) he reaches to pick up the star beanbag and a bee lands on him. The other positive story was about a boy who feels happy when he and his sister have a silly time chasing fireflies with a purple net and who later feels happy again when he is getting ready for a picnic and (1) he finds his needed shoes next to the purple net, or (2) he spills his milkshake next to the purple net.

The format of behavior-cuing stories closely resembled emotion-cuing stories with only three differences: (1) during the past event the target character engaged in a particular action rather than expressed 

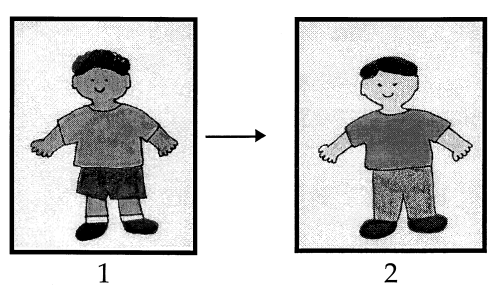

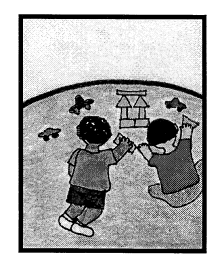

3

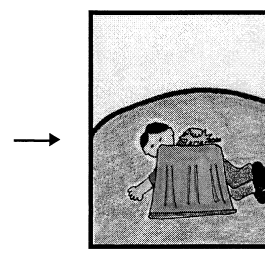

4

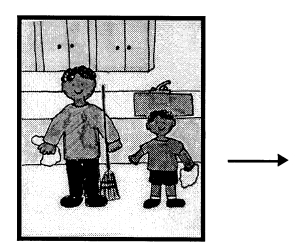

6

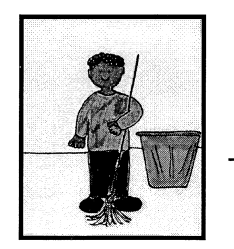

7

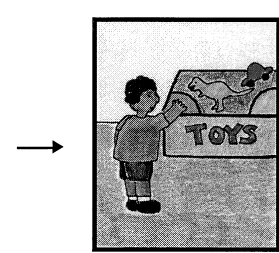

5

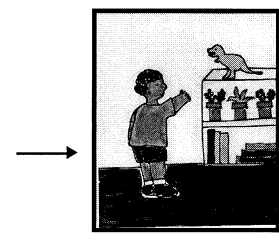

8
Figure 2 Illustrations for a behavior-cuing story used in Study 1 shown in reduced form.

an emotion; (2) during the current situation the cue elicited changes in the character's behavior; and (3) there was no match-mismatch distinction. Figure 2 shows the illustrations for a behavior-cuing story about a boy who searches for his t-rex dinosaur after he and his friend decide to pretend play "dinosaur mountain" with an orange bucket. Many days later the boy looks for his t-rex dinosaur again when he sees his father take the orange bucket and mop out of the closet to clean. The other behavior-cuing story featured a girl who wears her grandfather's green-striped scarf while raking leaves with him and who many days later runs to look at the leaves again when she sees the green-striped scarf drop onto the closet floor.

During the testing procedure, 4-year-olds, 5-yearolds, and adults listened to six stories as the experimenter attached the picture cards on an upright board. For these age groups, each participant received two emotion-match stories (one positive emotion-match and one negative emotion-match), two emotionmismatch stories (one positive emotion-mismatch and one negative emotion-mismatch), and two behaviorcuing stories. The number of scenarios for 3-year-olds was reduced, as in Lagattuta et al. (1997), because of the increased time required to narrate the stories and elicit coherent explanations in such young children. Thus, 3-year-olds listened to a set of three stories with one trial of each core story type (i.e., emotion-match, emotion-mismatch, behavior). The presentation of different story types was randomized and counterbalanced across participants.

We followed the same questioning format as that used in Studies 2 and 3 of Lagattuta et al. (1997). To ensure that the initial event of each story was understood, the experimenter asked participants to explain the cause of the character's original emotion or behavior: "Why is [character] [sad, mad, happy]/[doing that action]?" (the control question). At the conclusion of the final scenario where the cue appears, the experimenter asked participants to explain the character's emotional or behavioral reaction. More specifically, the test question for emotion-cuing stories was "Why does [character] start to feel [sad, mad, happy] right now?" The parallel test question for behavior-cuing stories was "Why is [character] [doing that action] right now?" A supplementary test question was asked if the participant explained that a character was remembering the past event but he or she did not mention the cue: "What made [character] think about the [past event] right now?" If participants explained a character's emotion or behavior by referring to the past event but they did not use mental language (e.g., "Mary's sad because her rabbit ran away") the experimenter asked the thinking prompt: "Is [character] thinking about [the past event] right now?" To help participants clarify and extend their explanations the experimenter paraphrased responses and encouraged additional explanations. For example, if a child responded, "Mary's sad because she doesn't like that dog anymore," the experimenter would ask, "Why doesn't Mary like that dog anymore?" Only after the child continued to provide no response or repeatedly answered "I don't know" did the experimenter continue with the next story. Stein and her colleagues (e.g., Liwag \& Stein, 1995; Stein \& Levine, 1989) have argued that more extensive clarification and questioning of children's responses of the sort used here helps young children more clearly reveal their reasoning.

After explaining the target character's emotion or behavior, participants were asked the other person's reaction question on three story trials (an emotionmatch, an emotion-mismatch, and a behavior-cuing story). This forced-choice question required participants to predict the emotional or behavioral reaction of a second person in the current situation; for example, "What about Amy? Amy also sees the spotted dog. How does Amy feel right now, sad or OK?" For behavior-cuing stories this was modified; for example: “What about Matthew's dad? Matthew's dad also sees the orange bucket. Will he just keep cleaning the kitchen, or run to find the t-rex dinosaur too?" The order of the forced-choice alternative was counterbal- 
anced so that participants biased to choose always the first or second alternative would perform at chance.

All participants were interviewed individually by a white female experimenter in a private room. Their responses were tape-recorded and transcribed verbatim. The testing procedure lasted approximately $15 \mathrm{~min}$.

\section{Results}

Explanations were rich and varied. Our content analyses focused specifically on whether participants explained current emotions in terms of the character's past experience, the character's thinking, or by connecting the character's thinking about the past to a current cue by providing a cognitive cuing explanation.

\section{Prior Experience Explanations}

Coding. First, we examined whether children and adults explained a character's current emotion or behavior as connected to his or her past history. Prior experience explanations included mention of any of the following as the reason for the character's current reaction: (1) the past event itself (e.g., "Mary's sad because her rabbit is gone"); (2) a current attitude, emotion, belief, or thought related to the prior experience (e.g., "Anne's mad because she doesn't like that clown anymore"); or (3) seeing the cue from the past event (e.g., "He's looking for the dinosaur because he sees that same orange bucket"). Contrast these to current experience explanations that focused exclusively on the present situation, as in: "He's happy because he thinks the bee has pretty colors," and "She's looking out the window because it's sunny."

All explanations were coded as either prior experience or current experience explanations by a primary coder. Independent coding of $50 \%$ of the transcripts for each age group by a second person yielded $98 \%$ interrater agreement. All discrepancies were resolved by discussion.

Analyses. Although current experience explanations were offered by nearly all children and adults during questioning, the clear majority of participants (96\%) explained at least once that a character's present feelings or actions had been caused by a distal past experience. Initial analyses focused on the frequency of these past-oriented causes by assigning a score from 0 to 6 for the number of story trials for which children and adults provided prior experience explanations. For these and all other analyses, the scores of 3-year-olds (who received only three story trials) were doubled so that analyses could be conducted on an equivalent scale.
Table 1 Study 1: Percentage of Prior Experience Explanations by Age and Story Type

\begin{tabular}{lcccc}
\hline & \multicolumn{4}{c}{ Age } \\
\cline { 2 - 5 } Category of Analysis $^{n}$ & 3 & 4 & 5 & Adult \\
\hline Across all stories $^{\mathrm{a}}$ & 39 & 47 & 64 & 95 \\
Emotion-cuing stories $^{\mathrm{b}}$ & & & & \\
$\quad$ Emotion-match & 30 & 22 & 50 & 94 \\
$\quad$ Positive emotion & 13 & 33 & 50 & 94 \\
$\quad$ Negative emotion & 38 & 39 & 56 & 94 \\
Emotion-mismatch & 80 & 83 & 89 & 100 \\
$\quad$ Positive emotion & 33 & 53 & 70 & 97 \\
$\quad$ Negative emotion & & & & \\
Behavior-cuing stories & 33 &
\end{tabular}

a Percentage of prior experience explanations out of six trials per participant (out of three for 3-year-olds).

b Percentage of prior experience explanations out of one trial per participant for each emotion cuing story combination, out of two trials for behavior cuing stories; out of a reduced set for 3-yearolds (see footnote 1).

Table 1 presents the primary results. As shown in the top row of the table, the frequency of prior experience explanations increased during the preschool years and between childhood and adulthood. An Age (4) $\times$ Gender (2) ANOVA resulted in a main effect for age $F(3,64)=22.21, p \leq .001$. Tukey's Honestly Significant Difference (HSD) comparisons showed that adults more often connected characters' current emotions or behaviors to past experience than 3-, 4-, or 5 -year-olds and that 5-year-olds mentioned a character's prior history more frequently than 3-year-olds, $p s \leq .01$. Gender was not significant (for males, $M=$ $59 \%$ explanations; for females, $M=64 \%$ explanations) and will not be considered further.

Next, we examined whether prior experience explanations varied by story type. Recall that scenarios varied along three dimensions: (1) whether the emotion was unusual versus typical for the current situation (emotion-situation fit); (2) whether the emotion was positive or negative (emotion valence); and (3) whether the type of reaction to be explained was emotional or behavioral. Because 3-year-olds did not receive one trial of all four types of emotion-cuing stories ${ }^{1}$ and

\footnotetext{
${ }^{1}$ Note that counterbalancing the three core story types (emotion-match, emotion-mismatch, and behavior) across three story trials for eighteen 3-year-olds (with the constraint that each child heard one positive emotion, one negative emotion, and one behavior story) resulted in 18 behavior cuing trials, 10 negative emotion-mismatch trials, 8 negative emotion-match trials, 8 positive emotion-mismatch trials, and 10 positive emotion-match trials for the 3-year-olds as a group.
} 
adults provided prior experience explanations for nearly all story trials (96\% explanations), the following analyses focus on 4- and 5-year-olds. Explanations for emotion-cuing stories are analyzed first and then compared with explanations for behaviorcuing stories.

The main body of Table 1 shows the primary results. An Age (2: 4- or 5-year-olds) $\times$ Emotion-Situation Fit (2: emotion-match or emotion-mismatch) $\times$ Emotion Valence (2: positive or negative) repeated measures ANOVA yielded a main effect for emotion-situation fit, $F(1,34)=13.28, p \leq .001$, and valence, $F(1,34)=$ $14.70, p \leq .001$, qualified by a significant Fit $\times$ Valence interaction, $F(1,34)=6.80, p \leq .01$. As evident in Table 1 , the effects for valence and emotion-situation fit were driven by 4- (83\% explanations) and 5-yearolds' (89\% explanations) high performance on negative emotion-mismatch stories. These stories that combined negative emotions with mismatched conditions (e.g., feeling mad upon receiving a balloon from a clown) were particularly compelling to 4 - and 5-yearolds. They elicited more frequent references to prior experience than all other emotion-cuing story types, $p s \leq .01$, Tukey's HSD (all other pairwise ns). Although not included in formal analyses, the data from 3-year-olds and adults also clearly manifest this pattern, with the highest frequency of prior experience explanations being for negative emotion-mismatch stories.

Prior experience explanations for behavior-cuing stories were then compared with their responses for emotion-cuing stories. An Age (2) $\times$ Story Type (3: behavior, emotion-match, emotion-mismatch) repeated measures ANOVA yielded a main effect for story type, $F(2,68)=7.50, p \leq .001$. Tukey's HSD comparisons revealed that prior experience responses were offered more frequently for emotion-mismatch stories ( $M=67 \%$ explanations) and behavior-cuing stories ( $M=63 \%$ explanations) than for emotion-match stories $(M=39 \%$ explanations), $p s \leq .05$. An additional Age (2) $\times$ Story Type (2) ANOVA compared performance on behavior cuing stories with just negative emotion-mismatch stories. Here, a main effect for type, $F(1,34)=9.65, p \leq .01$, revealed that 4 - and 5-yearolds used prior experience more often to explain unusual negative emotions ( $M=86 \%$ explanations) than to explain behaviors ( $M=63 \%$ explanations). Therefore, whereas preschoolers equally attributed the cause of both actions and emotions to a person's past history, they revealed most cogent knowledge about the influence of prior experience when a person was feeling sad or mad in a typically positive situation. Again, note that this same pattern holds for 3-year-olds as well.

\section{Thinking Explanations}

Coding. Further analyses examined how children and adults bridged together a character's current and prior circumstances in their explanations for emotions and behaviors. In particular, we focused on the frequency with which participants explained that a person's current reaction was caused by remembering, thinking, or being reminded about the prior event, such as, "She's mad because she's remembering her lost rabbit," or "He's happy because he's thinking about that trick." Such thinking explanations are important for two reasons. They not only measure young children's knowledge about the presence and influence of active mental ideation, or thinking, a topic of recent theoretical debate (see Estes, 1998; Flavell et al., 1995; Lagattuta et al., 1997); but they also provide a further test of the significance of story type on explanations for actions or feelings, particularly, the salience of the mismatched negative emotions.

Recall that a thinking prompt was included during questioning if a child or adult referred to the past event but did not explicitly refer to thinking, remembering, etc.: "Is [character] thinking about [past event] right now?" Thus, thinking explanations were coded as either prompted or unprompted following the criteria established by Lagattuta et al. (1997). Unprompted explanations were those in which the participant spontaneously referred to thinking in reference to the past event (e.g., "She's sad because she's remembering her rabbit being gone"), whereas prompted explanations were those in which the participant directly referred to the past event (e.g., "She's sad because her bunny is still gone") and then asserted in response to the thinking prompt that the character was remembering that prior experience.

Note that the mere inclusion or omission of a mental term did not determine whether an explanation was coded as a thinking explanation. For example, children and adults could not simply use the word "think" in their explanation (e.g., "I think he's happy because he found that quarter"). Instead, the word had to be used causally and in reference to the story character (e.g., "He's happy because he's thinking about his sister"). Moreover, when participants did not use mental terms spontaneously in their responses, they could still provide a thinking explanation with the aid of the prompt.

Reliability based on $50 \%$ of the transcripts for each age group resulted in $98 \%$ interrater agreement for thinking explanations, including whether the response was prompted or unprompted. All discrepancies were resolved by discussion. 
Table 2 Study 1: Percentage of Thinking Explanations by Age and Story Type

\begin{tabular}{lcccc}
\hline & \multicolumn{4}{c}{ Age } \\
\cline { 2 - 5 } Category of Analysis & 3 & 4 & 5 & Adult \\
\hline Across all stories $^{\mathrm{a}}$ & $28(7)$ & $35(18)$ & $60(39)$ & $94(84)$ \\
Emotion-cuing stories & & & & \\
$\quad$ Emotion-match & & & 44 & 94 \\
$\quad$ Positive emotion & 20 & 11 & 50 & 89 \\
$\quad$ Negative emotion & 0 & 22 & & \\
Emotion-mismatch & & & 39 & 94 \\
$\quad$ Positive emotion & 38 & 28 & 89 & 100 \\
$\quad$ Negative emotion & 50 & 72 & 67 & 97 \\
Behavior-cuing stories & 28 & 39 & 67 \\
\hline
\end{tabular}

a Percentage of total thinking explanations (prompted and unprompted combined) out of six trials per participant (out of three for 3-year-olds), with the percentage of unprompted thinking explanations shown in parentheses.

b Percentage of total thinking explanations out of one trial per participant for each emotion-cuing story combination, out of two trials for behavior-cuing stories; out of a reduced set for 3-year-olds (see footnote 1).

Analyses. Participants received a score from 0 to 6 for the number of story trials for which they offered thinking explanations (either prompted or unprompted), known as their total thinking score. In Table 2 data are presented for both total thinking and unprompted thinking responses (unprompted responses appear in parentheses), but statistical analyses are reported on only the total score data. Identical ANOVAs on just the unprompted scores yielded the same trends and differences as those reported for total scores.

As shown in the top row of Table 2, an Age (4) $\times$ Gender ANOVA for total thinking explanations resulted in a main effect for age, $F(3,64)=28.09, p \leq$ .001. Whereas only a minority of the explanations provided by 3 - and 4-year-olds claimed that characters were currently thinking about a prior incident, the majority of 5-year-olds' and adults' did so. All between-age comparisons were significant, except for the difference between 3- and 4-year-olds (Tukey's HSD), $p s \leq .05$. Again, gender was not significant (for males, $M=54 \%$ explanations; for females, $M=55 \%$ explanations) and will not be considered further.

The main body of Table 2 shows the influence of story type on total thinking explanations. Again, data are presented for 3-year-olds and adults but the analyses are focused on 4- and 5-year-olds. An Age (2) $\times$ Emotion-Situation Fit (2) $\times$ Emotion Valence (2) repeated measures ANOVA resulted in a main effect for age, $F(1,34)=4.92, p \leq .03$, for fit, $F(1,34)=25.37, p \leq$ .001 , and for valence, $F(1,34)=12.75, p \leq .001$, and a significant Fit $\times$ Valence interaction, $F(1,34)=9.05$, $p \leq .005$. Consistent with the prior experience analyses, the effects for emotion-situation fit and emotion valence resulted from the high frequency of thinking explanations that $4-(M=72 \%$ explanations $)$ and 5-year-olds ( $M=89 \%)$ gave for negative emotionmismatch stories. Tukey's HSD comparisons confirmed that negative emotion-mismatch stories yielded more frequent references to thinking about the past than the other three kinds of emotion-cuing stories, $p$ s $\leq .01$ (all other pairwise ns). Moreover, a separate Age (2) $\times$ Story Type (2) ANOVA found that 4- and 5 -year-olds demonstrated more sophisticated awareness about when characters were thinking about the past in their explanations for unusual negative emotions ( $M=81 \%$ explanations) than in their explanations for actions $(M=53 \%), F(1,34)=10.97, p \leq .002$.

Analyses of thinking explanations thus replicated the results from prior experience analyses. Four- and 5 -year-olds more frequently explained that a person who felt sad or mad in a currently positive situation was "thinking about the past" than a person who displayed matched negative emotions or matched or mismatched happiness or who performed some action. Importantly, then, unusual negative emotions not only make past-present linkages more salient to young children but also encourage preschoolers to consider that characters might be thinking about something. Although excluded from the formal analyses, it is noteworthy that 3-year-olds' explanations produced the same pattern of results: The highest frequency of thinking explanations $(M=50 \%$ explanations) were in the context of explaining why a character felt negative emotions in a positive situation. Moreover, negative emotion-mismatch stories were the only story type that elicited a full $100 \%$ thinking explanation from adults.

\section{Cognitive Cuing Explanations}

Coding. Final analyses focused on a more stringent, yet compelling, measure of children's knowledge about past events and thinking - their ability to explain not only that a character is remembering a past event but also why he or she started to have these thoughts. Cognitive cuing explanations, such as, "She's mad because the clown makes her think about her doll" are especially revealing because they require coherent understanding about three interrelated concepts: the character's feeling or action was caused by (1) the cue in the current scene that (2) made the character think about (3) the past event. Cognitive cuing explanations are distinct from thinking explanations in that the participant had to explain that the charac- 
ter's action or emotion was caused by thinking about the past, and further that these thoughts had been triggered by a particular cue, or reminder, in the current situation.

Interrater reliability for cognitive cuing explanations based on $50 \%$ of the transcripts at each age period, including whether a response was prompted or unprompted, was $98 \%$. Unprompted cognitive cuing explanations were those in which the participant used mental language spontaneously when referring to the past event. An example of a prompted cognitive cuing explanation is as follows: Experimenter: Why did Anne start to feel mad right now? Child: Because her doll is broken. Experimenter: Is she thinking about her broken doll right now? Child: Yes. Experimenter: What made her start to think about her doll right now? Child: The clown. All discrepancies were resolved by discussion.

Analyses. Preschoolers and adults received a score from 0 to 6 for the number of story trials for which they offered either a prompted or unprompted cognitive cuing response, their total cognitive cuing score. Table 3 presents the primary results of these total scores (again data for unprompted responses alone are shown in parentheses). As shown in the top row of the table, an Age $(4) \times$ Gender ANOVA resulted in a main effect for age, $F(3,64)=39.28, p \leq .001$, and no effect for gender (for males, $M=45 \%$; for females, $M=46 \%$ explanations). As with thinking explanations, Tukey's HSD comparisons revealed that all pairwise comparisons for age were significant except for the difference between the 3- and 4-year-olds, $p s \leq .05$.

The main body of Table 3 presents data for story type. Confirming the pattern found in the two preceding analyses, an Age (2) $\times$ Emotion-Situation Fit (2) $\times$ Valence (2) repeated measures ANOVA for total cognitive cuing responses resulted in a main effect for age, $F(1,34)=5.68, p \leq .02$, for emotion-situation fit, $F(1,34)=12.88, p \leq .001$, and for valence, $F(1,34)=$ $11.18, p \leq .002$, and a Significant Emotion-Situation Fit $\times$ Emotion Valence Interaction, $F(1,34)=5.41, p \leq$ .03. Again, most striking was the greater frequency with which 4 - ( $M=44 \%$ explanations) and 5-year-olds $(M=83 \%)$ explained characters' mismatched negative emotions in relation to cognitive cuing: performance on this story type was significantly higher than on any other kind of emotion-cuing or behaviorcuing story, $p s \leq .01$. Thus, even under the most stringent criteria, cognitive cuing explanations, preschoolers demonstrated the greatest knowledge about interrelationships between mind, emotion, and the past in their explanations for why a person was feeling sad or mad in a conventionally happy situation.
Table 3 Study 1: Percentage of Cognitive Cuing Explanations by Age and Story Type

\begin{tabular}{lcccc}
\hline & \multicolumn{4}{c}{ Age } \\
\cline { 2 - 5 } Category of Analysis & 3 & 4 & 5 & Adult \\
\hline Across all stories $^{\mathrm{a}}$ & $13(2)$ & $24(11)$ & $49(33)$ & $94(84)$ \\
Emotion cuing stories $^{\mathrm{b}}$ & & & & \\
$\quad$ Emotion-match & & & 39 & 94 \\
$\quad$ Positive emotion & 10 & 6 & 39 & 89 \\
$\quad$ Negative emotion & 0 & 22 & & \\
Emotion-mismatch & & & 33 & 94 \\
$\quad$ Positive emotion & 25 & 22 & 83 & 100 \\
$\quad$ Negative emotion & 20 & 44 & 53 & 97 \\
Behavior-cuing stories & 11 & 25 & 53 \\
\hline
\end{tabular}

${ }^{\text {a }}$ Percentage of total cognitive cuing explanations (prompted and unprompted combined) out of six trials per participant (out of three for 3-year-olds), with the percentage of unprompted cognitive cuing explanations shown in parentheses.

${ }^{b}$ Percentage of total cognitive cuing explanations out of one trial per participant for each emotion-cuing story combination, out of two trials for behavior-cuing stories; out of a reduced set for 3-year-olds (see footnote 1 ).

\section{Other Person's Reaction Question}

To examine whether preschoolers and adults viewed the target character's feelings or actions in the final scene as person specific, participants were given a prediction score from 0 to 3 for the number of trials for which they predicted a different behavioral or emotional reaction for the secondary character. An age (4) ANOVA for prediction scores yielded a main effect for age, $F(3,68)=3.51, p \leq .02$. Tukey's HSD tests revealed that adults ( $M=96 \%$ predictions) more frequently predicted that the other person would have a different reaction than 3- $(M=74 \%)$ or 5-yearolds $(M=74 \%), p s \leq .05$. Four-year-olds $(M=81 \%$ predictions) did not differ from any age group. More importantly, however, $t$ tests confirmed that all age groups' performance was higher than would be expected by chance, $p s \leq .01$. Therefore, both children and adults demonstrated knowledge that the same situation can elicit different actions and feelings in different people.

\section{Discussion}

Consistent with Lagattuta et al. (1997), significant developmental changes were observed from 3 to 5 years of age in children's understanding about the influence of past events, thinking, and cognitive cuing on a person's current reactions. For example, whereas only a minority of 3-year-olds' responses explained a person's present action or emotion in terms of think- 
ing or being reminded about the past, the majority of explanations provided by 5 -year-olds and adults included such historical-mental connections (e.g., "Anne's mad because seeing the clown makes her remember her broken doll").

Confirming the earlier findings by Lagattuta et al. (1997), even very young children exhibited remarkable insights about connections between past history, mind, and current experience in some situations. Indeed, when asked to explain why a person started to feel sad or mad in a currently positive situation (negative emotion-mismatch) $80 \%$ of the 3-year-olds, $83 \%$ of the 4 -year-olds and $89 \%$ of the 5 -year-olds attributed characters' current emotions to their prior experiences (e.g., "Mary's sad because the dog chased the rabbit away"). Moreover, preschoolers went beyond just connecting current emotions to past history: They linked past and present through mental activity. The majority of 3- to 5-year-olds (50\% 3-, 72\% 4-, 89\% 5year-olds) explained that unusual negative emotions were caused by thinking about the past (e.g., "Mary's sad because she's remembering her rabbit"), with $20 \%$ (3-year-olds), 44\% (4-year-olds) and 83\% (5-yearolds) providing a complete cognitive cuing explanation (e.g., "She's sad because the dog makes her think about her lost bunny"). Thus, young children demonstrated a sophisticated appreciation of how active, mental recollections of past negative experiences can make a person feel sad or mad even when these thoughts are at odds with current conditions.

Still, such burgeoning insights about connections between current experience, the mind, and the past were not evident in other kinds of affective situations, situations for which adults explained emotions in terms of prior experience, thinking, and cognitive cuing nearly $100 \%$ of the time. For example, when a character's anger or sadness matched a current negative event (e.g., Mary feels sad when the dog tramples her flowers), few preschoolers (0\% 3-year-olds, $22 \%$ 4-year-olds, 50\% 5-year-olds) suggested that the protagonist was thinking about the past. Rather, young children often explained typical negative emotions as caused by specific events in or character's appraisals of the current situation (e.g., "She's sad because she didn't want her flowers ruined"). Preschoolers also rarely explained people's happiness, even happiness that mismatched a current negative situation (e.g., happy despite a big bee on one's arm; happy after spilling a yummy milkshake) as caused by remembering a positive past experience $(M=23 \%)$. Not only were preschoolers less aware that characters might be thinking in these situations, but they also made fewer connections to prior experience in general for matched negative emotions (13\% 3-year-olds, 33\% 4-year-olds, 50\% 5-year-olds) and for matched and mismatched positive emotions (33\% 3-year-olds, $31 \%$ 4-year-olds, $53 \%$ 5-year-olds). To be clear, it is not that preschoolers' explanations for these kinds of emotional situations were not legitimate, sensible, or coherent; rather, these explanations were just not framed in relation to past history or the mind as were the adults'.

The reluctance of preschoolers to explain atypical positive emotions in relation to thinking or past experience is perhaps most noteworthy. One explanation, consistent with Stein and Levine $(1987,1989)$, is that young children understand happiness to result not only from the achieving or maintaining of goals, but also from avoiding undesirable outcomes. Thus, children may have focused on the salience of the immediate danger (having a bee on your arm) or negative outcome (spilling a milkshake) in the current situation. Indeed, in their explanations for mismatched positive emotions, some children did suggest that happiness resulted from avoiding a potential negative outcome (e.g., "Frank's happy because the bee didn't sting him"). Other explanations included ascribing idiosyncratic desires and beliefs to the protagonist (e.g., "He's happy because maybe he doesn't like milkshakes"), or often, simply "I don't know." Another interpretation is that despite young children's early awareness that negative thoughts can sabotage positive situations, they do not endorse the complementary view that positive thoughts can make a person feel happy in a negative situation. Namely, positive thoughts alone cannot override a clearly negative situation. This is certainly consistent with children's coping literature showing low endorsement and awareness of "positive thinking" strategies in children under age 7 (Altshuler \& Ruble, 1989; Harris \& Lipian, 1989). In the words of one 4-year-old, "When a bee is tickling you can't think!"

What about the comparison between behaviors and emotions? On the basis of the findings from Flavell et al. (1995) and Lagattuta et al. (1997), it was hypothesized that young children's understanding of past events, thinking, and cognitive cuing would be advanced for emotional situations. This hypothesis requires revision. Again, it is the special status of mismatched negative emotions that stands out, rather than emotions per se. Three- and 4-year-olds were nearly twice as likely to explain characters' mismatched negative emotions in terms of cognitive cuing $(20 \%$ 3 -year-olds; $44 \%$ 4-year-olds) or thinking about the past (50\% 3-year-olds; $72 \%$ 4-year-olds) than characters' behaviors (cognitive cuing $=11 \%$ 3-year-olds, $25 \%$ 4-year-olds; thinking $=28 \%$ 3-year-olds, $39 \%$ 4-year-olds); with 5-year-olds following the same, but 
less extreme, pattern. Excluding negative emotionmismatch stories, however, preschoolers' explanations for behavior-cuing situations were the same as, or more sophisticated than, their explanations for other emotion-cuing situations. In contrast, no emotional situation took precedence for adults.

\section{STUDY 2}

The focus of this research thus far has been on children's explanations for the emotions of the target character, a person for whom relevant past history information is known. As a control in Study 1, we asked children to predict how another person, naïve to the past event, would react to the scene where the cue appeared. Even 3-year-olds consistently predicted that this other person would experience different emotions than the target character $(74 \%$ accuracy). This task provided a critical check that young children understand that the same situation can elicit different emotions in different people.

An additional question concerns whether such contrasting emotional reactions influence children's explanations for feelings. Indeed, divergent personto-person emotions represent another kind of "mismatched" emotional context, a mismatch between two people's emotional evaluation of the same event. Perhaps the presence of two people experiencing different emotions in the same situation facilitates children's awareness of the link between mind and emotion by highlighting the peculiarity of the target character's feelings. We know from related developmental and social psychological research that children's and adults' emotional reactions to events can be influenced by how the people around them are acting and feeling (Darley \& Latane, 1968; Latane \& Darley, 1968; Schachter \& Singer, 1962) and that even as infants we often look to, or socially reference, others' emotional expressions to guide our interpretations of novel experiences (Baldwin \& Moses, 1996; Campos \& Sternberg, 1981; Feinman \& Lewis, 1983; Mumme, Fernald, \& Herrera, 1996). Arguably, then, children's and adults' explanations for emotions may likewise be shaped by similarities or differences in how different people react to the same situation.

Study 2, therefore, examined the relative influence of both emotion-situation fit and person-person fit on children's and adults' reasoning about the causes of emotions, particularly mental causes. As with Study 1, emotion-situation fit indicates whether a person's emotion is conventional (emotion-match) or unusual (emotion-mismatch) for the current circumstances. In contrast, person-person fit denotes whether two people in the same situation display identical
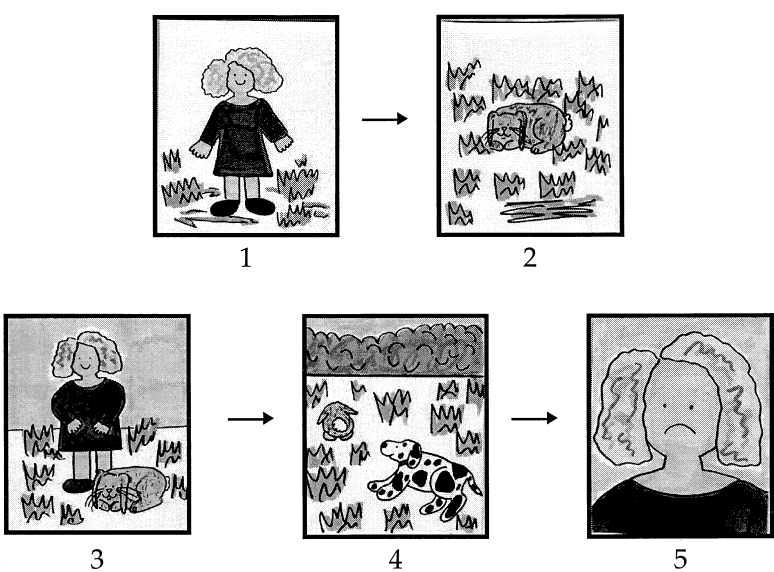

5

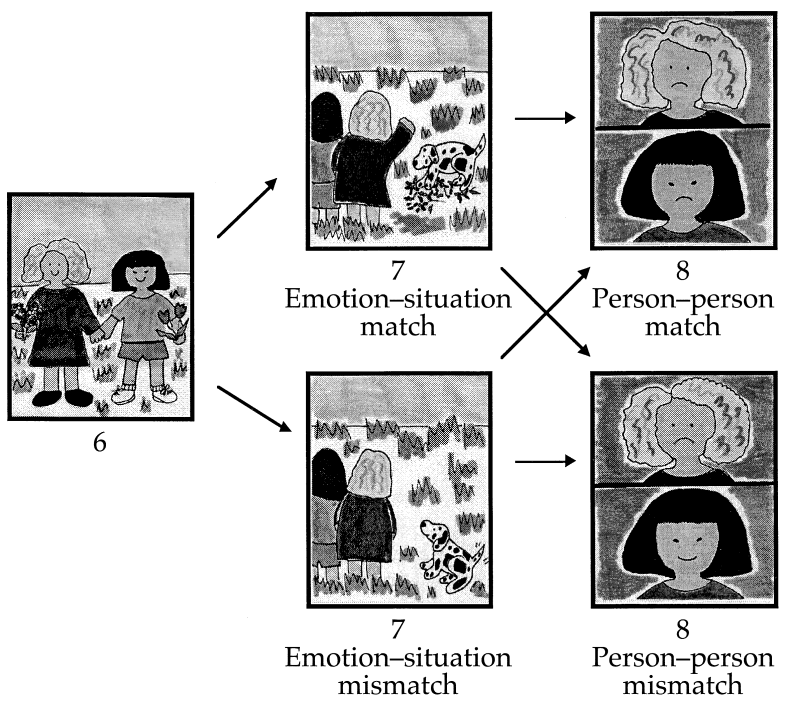

Figure 3 Illustrations for an emotion-cuing story used in Study 2 shown in reduced form.

(person-person match) or divergent affective reactions (person-person mismatch). To maintain equivalence across story scenarios, all stories in Study 2 featured negative past events and current anger or sadness in the target characters.

Figure 3 depicts how the story scenarios for Study 2 encompassed these varying degrees of emotionsituation fit and person-person fit. Here again, Mary feels sad after her rabbit is chased away by a blackspotted dog. Many days later she feels sad again after the dog wags his tail (emotion-mismatch), or knocks down her flowers (emotion-match). For one ending, Mary's friend feels sad too (person-person match), and for the other, she feels happy instead (personperson mismatch). Participants were asked to explain the cause of both characters' feelings.

Note that in this story format the two characters displaying emotions, the target character and the secondary character, have different personal connections 
to the cue in the current situation. Whereas the target character has seen the cue before (e.g., Mary saw that dog chase her rabbit), the other person is seeing the cue for the first time. Study 2, therefore, also examined whether access to relevant past history information affects how children and adults interpret the causes of emotions. That is, for all story trials participants had to provide explanations for people's feelings when they had knowledge about their past (the target characters) and when they did not (secondary characters).

Study 2 additionally included some older children. Three-year-olds were excluded and early gradeschool children added for two reasons: (1) the inclusion of additional open-ended questions about the secondary character increased the complexity of the task; and (2) we reasoned that the use of personperson emotion information may develop later because children become more cognizant about how they compare with other people starting around the ages of 6 to 8 (Butler, 1990; Ruble, Boggiano, Feldman, \& Loebl, 1980; Stipek, Recchia, \& McClintic, 1992).

\section{Method}

\section{Participants}

Eighty children and adults participated: twenty 4-year-olds $(M=4,7$, range $=4,1-5,0)$, twenty 5year-olds $(M=5,6$, range $=5,1-6,0)$, twenty 6 - and 7 -year-olds $(M=7,1$; range $=6,1-8,0)$, and twenty young adults $(M=19,2$, range $=18,2-21,3)$ with equal numbers of males and females in each age group. Children came from two local preschools and one grammar school serving middle- to upper-middleclass families, and college students were recruited from a large midwestern university. Combined, the participants were 77\% European American, 14\% Asian American, and 9\% other ethnicities. There was no overlap in participants from Study 1 to Study 2.

\section{Materials and Procedures}

Emotion cuing stories (as in Figure 3) featured a target character who experiences an event that makes him or her sad or angry (lost pet, broken doll, stolen teddy bear, bicycle hit by car). Many days later, he or she encounters a visual cue related to the past negative event in either a pleasant or upsetting current situation and starts to feel sad or mad again. A secondary character, a friend, is also at the current event and he or she either feels the same negative emotion or feels happy instead. That is, each story had four possible endings that covered the four combinations of emotion-situation fit and person-person fit. Specifically, the target character's emotion (1) matched the situation and matched the other person's emotion (MS-MP); (2) mismatched the situation but matched the other person's emotion (MMS-MP); (3) matched the situation but mismatched the other person's emotion (MS-MMP); or (4) mismatched the situation and mismatched the other person's emotion (MMS-MMP).

During the testing procedure, 4-, 5-, and 7-year-olds and adults listened to four stories as the experimenter attached colorful picture cards onto an upright board. Each participant received one story trial of each of the four combinations of emotion-situation and personperson fit. The order of the different story types was randomized and counterbalanced across participants.

After the initial event, participants were told and pictorially shown the target character's facial expression (sad or mad) and were asked the control question, "Why is [character] [sad or mad] right now?" At the conclusion of the final event where the cue appears, participants were informed through pictures and words about the target character's feelings as well as the emotional reaction of the secondary character (the different emotions were clearly juxtaposed; see Figure 3). The experimenter first asked participants to explain the cause of the target character's emotion and then to provide an explanation for the secondary character's reaction. More specifically, the test questions were (1) "Why did [the target character] start to feel [sad or mad] right now?"; and (2) "Why do you think [the secondary character] feels [sad or mad] too?" or "Why do you think [the secondary character] feels happy instead?" The administration of the supplementary test question as well as the thinking prompt followed the same criteria as in Study 1. Again, the experimenter helped participants clarify their responses by paraphrasing their explanations and encouraged them to provide multiple explanations or guesses. Questioning for each story trial did not end until the child repeatedly answered "I don't know" or provided no additional responses.

All participants were interviewed individually by one of two white female experimenters (each experimenter interviewed half of the participants in each age group) in a private room. All responses were tape-recorded and transcribed verbatim. The procedure lasted about $15 \mathrm{~min}$.

\section{Results \\ Coding \\ Explanations for the target characters' and secondary characters' emotions were coded into the same four}


categories as in Study 1: (1) current experience, (2) prior experience, (3) thinking, and (4) cognitive cuing. The same criteria were used to distinguish prompted from unprompted thinking and cognitive cuing explanations. Recall that these categories are "embedded" in the sense that thinking explanations were also coded as prior experience explanations (i.e., thinking $=$ prior experience + thinking), and cognitive cuing explanations were also coded as both thinking and prior experience explanations (i.e., cognitive cuing $=$ prior experience + thinking + cue).

To verify the accuracy of the coding, $50 \%$ of the transcripts were coded by two independent raters. This resulted in $98 \%$ interrater reliability across all three categories for target and secondary character explanations, including whether the explanations were prompted or unprompted. All discrepancies were resolved by discussion.

\section{Analyses}

Target character: Prior experience explanations. We begin again with the fundamental distinction of whether young children and adults made a connection between a character's present emotions and his or her distal past experience, a prior experience explanation (e.g., "He's mad because that car smashed his bicycle"). Children and adults received a score from 0 to 4 for the number of story trials that they explained a character's current feelings in relation to his or her past.

Table 4 presents the primary results. As shown in the top row of the table, the consistency of prior experience explanations increased with age. An Age (4) $\times$ Gender (2) ANOVA resulted in a main effect for age,

Table 4 Study 2: Percentage of Prior Experience Explanations by Age and Story Type

\begin{tabular}{lcccc}
\hline & \multicolumn{5}{c}{ Age } \\
\cline { 2 - 5 } Category of Analysis & 4 & 5 & 7 & Adult \\
\hline Across all stories $^{\mathrm{a}}$ & 55 & 66 & 85 & 96 \\
$\begin{array}{l}\text { By story type } \\
\text { Emotion matches situation }\end{array}$ & & & & \\
$\quad$ Matches other person & 35 & 50 & 80 & 90 \\
$\quad$ Mismatches other person & 40 & 65 & 80 & 95 \\
$\quad$ Emotion mismatches situation & & & & \\
$\quad$ Matches other person & 75 & 75 & 90 & 100 \\
$\quad$ Mismatches other person & 70 & 75 & 90 & 100 \\
\hline
\end{tabular}

a Percentage of prior experience explanations out of four trials per participant.

${ }^{b}$ Percentage across one trial of each Emotion-Situation Fit $\times$ Person-Person Fit combination.
$F(3,72)=8.30, p \leq .001$. Pairwise comparisons (Tukey's HSD) showed that 7-year-olds more frequently explained present feelings as caused by a past event than did 4-year-olds and that adults provided more frequent references to prior experience than 4or 5 -year-olds, $p s \leq .05$. There were no significant differences between the 4- and 5-year-olds, or between 7 -year-olds and adults. Gender was not significant and will not be considered further.

The main body of Table 4 shows the effect of story type on prior experience explanations. Again, adults were excluded from the story type analyses because of their near ceiling performance. An Age (3: 4-, 5-, or 7-year-olds) $\times$ Emotion-Situation Fit (2: the target character's emotion matches or mismatches the present situation) $\times$ Person-Person Fit (2: the target character's emotion matches or mismatches the other person's) repeated measures ANOVA resulted in a main effect for age, $F(2,57)=4.43, p \leq .02$, and a main effect for emotion-situation fit, $F(1,57)=22.88, p \leq$ .001 , both qualified by an Age $\times$ Emotion-Situation Fit interaction that approached significance, $F(2,57)=$ $2.89, p \leq .06$. As with Study 1, 4- and 5-year-olds used prior experience more frequently to explain a person's negative emotion that mismatched versus matched the current situation (for 4-year-olds, $M \mathrm{~s}=$ $73 \%$ versus $38 \%$; for 5 -year-olds, $M$ s $=75 \%$ versus $58 \%$ ), $p$ s $\leq .05$ (simple effects). By age 7 , however, prior experience explanations were consistently offered regardless of the fit between a person's negative emotion and the situation. In contrast, personperson fit had no effect at any age: 4-, 5- and 7-yearolds (and adults) gave equivalent numbers of prior experience explanations for the protagonist when the secondary characters' emotions were the same $(M=68 \%$ explanations) as when they were different $(M=70 \%)$.

Target character: Mental activity explanations. As with Study 1, children and adults went beyond connecting present emotions to a person's past experience-they often bridged present and past through specific reference to what the character was currently thinking about or remembering, thinking explanations (e.g., "He's mad because he remembers when she stole his bear"). Indeed, many provided complete cognitive cuing explanations by explaining that a character was currently thinking about the past because he or she saw an associative cue, or reminder (e.g., "He's sad because the car makes him think about his broken bicycle"). Thus, we carried out two separate age (3: 4-, 5-, or 7-year-olds) $\times$ Emotion-Situation Fit $(2) \times$ Person-Person Fit (2) repeated measures ANOVAs: one for total thinking scores (0 to 4 for the number of trials for which participants provided either 
prompted or unprompted thinking explanations); and one for total cognitive cuing scores ( 0 to 4 for the number of trials for which they provided prompted or unprompted cognitive cuing explanations). Adults were excluded from these story type analyses because they provided thinking and cognitive cuing explanations for nearly all trials $(94 \%$ explanations).

Table 5 shows the primary results. Both thinking (top half) and cognitive cuing explanations (lower half) increased with age, $p \leq .001$. Tukey's HSD comparisons showed that 7-year-olds more frequently attributed emotions to thinking about the past and to cognitive cuing than 4 -year-olds, $p s \leq .01$. Five-yearolds were intermediate and did not differ from either age group. As with prior experience explanations, 4- and 5-year-olds more frequently linked anger or sadness to thinking about the past when these emotions mismatched versus matched a current negative situation (for 4-year-olds, $M s=55 \%$ versus $30 \%$; for 5 -year-olds, $M s=73 \%$ versus $53 \%$ explanations), $p s \leq$ .01. Moreover, 4- and 5-year-olds provided more cognitive cuing explanations for unusual versus conventional negative emotions (for 4-year-olds, $M \mathrm{~s}=$ $50 \%$ versus $23 \%$; for 5 -year-olds, $M$ s $=68 \%$ versus $35 \%$ explanations), $p \mathrm{~s} \leq .05$. By age 7 , children, like adults, consistently used thinking and cognitive cuing explanations for target characters' emotions across all situations. Again, person-person fit had no significant influence at any age.
Past history information: Target versus secondary characters. Recall that participants knew that the target character had experienced a negative prior encounter with the cue (e.g., the yellow car had broken Eric's bicycle), but they had no information about the secondary characters' past. Thus, the comparison of participants' explanations for the emotions of these two characters provides the needed contrast to examine the influence of past history information on children's understanding of persons' emotional, mental lives.

As a baseline, first consider the number of story trials (0 to 4) for which children and adults linked a character's emotions to their own or another person's prior experience (e.g., "She's sad because her rabbit ran away"; "She's mad because maybe that clown ruined her toy before too"). Table 6 shows the primary results. As shown at the top of the table, an Age (4) $\times$ Character (2) repeated measures ANOVA resulted in a main effect for character, $F(1,76)=293.24$, $p \leq .001$. At every age, prior experience was a common explanation for target characters' emotions $(M=$ $76 \%$ explanations). In contrast, it was rarely offered by 4-, 5-, 7-year-olds, or by adults for secondary characters' emotions ( $M=24 \%$ explanations). Rather, explanations for secondary characters most often focused exclusively on the current experience, such as, "He's mad because the girl knocked the tower down."

Next, consider a broader focus on mental explanations. Does past history information influence the

Table 5 Study 2: Percentage of Target Character Thinking and Cognitive Cuing Explanations by Age and Story Type

\begin{tabular}{|c|c|c|c|c|c|c|}
\hline \multirow[b]{3}{*}{ Category of Analysis } & \multirow[b]{3}{*}{ Age } & \multicolumn{5}{|c|}{ Story Type ${ }^{a}$} \\
\hline & & \multicolumn{2}{|c|}{$\begin{array}{l}\text { Emotion } \\
\text { Matches } \\
\text { Situation }\end{array}$} & \multicolumn{2}{|c|}{$\begin{array}{c}\text { Emotion } \\
\text { mismatches } \\
\text { situation }\end{array}$} & \multirow{2}{*}{$\begin{array}{c}\text { Across all } \\
\text { story types }\end{array}$} \\
\hline & & $\mathrm{MPc}^{\mathrm{c}}$ & $\mathrm{MMP}^{\mathrm{d}}$ & $\mathrm{MPc}^{\mathrm{c}}$ & $\mathrm{MMP}^{\mathrm{d}}$ & \\
\hline \multirow[t]{4}{*}{ Thinking explanations } & 4 & 30 & 30 & 50 & 60 & $43(11)$ \\
\hline & 5 & 45 & 60 & 75 & 70 & $63(23)$ \\
\hline & 7 & 75 & 75 & 85 & 90 & $81(44)$ \\
\hline & Adults & 85 & 90 & 100 & 100 & $94(61)$ \\
\hline \multirow[t]{4}{*}{ Cognitive cuing explanations } & 4 & 25 & 20 & 45 & 55 & $36(9)$ \\
\hline & 5 & 30 & 40 & 75 & 60 & $51(21)$ \\
\hline & 7 & 75 & 75 & 75 & 85 & $78(44)$ \\
\hline & Adults & 85 & 90 & 100 & 100 & $94(61)$ \\
\hline
\end{tabular}

a Percentage across one trial of each Emotion-Situation Fit $\times$ Person-Person Fit combination; all data are total scores.

${ }^{b}$ Percentage across four trials; percentage of unprompted explanations is shown in parentheses next to total score data.

c "MP" indicates that the target character's emotion matches the secondary character's emotion.

d "MMP" indicates that the target character's emotion mismatches the secondary character's emotion. 
Table 6 Study 2: The Influence of Past History Information on Explanations for Emotions

\begin{tabular}{lcccc}
\hline & & \multicolumn{2}{c}{ Past History Information } & \\
\cline { 3 - 4 } Category & Age & Known & Unknown $^{\mathrm{a}}$ & Combined $^{\mathrm{a}}$ \\
\hline Prior experience explanations & 4 & 55 & 19 & 37 \\
& 5 & 66 & 19 & 43 \\
& 7 & 85 & 25 & 55 \\
Internal-psychological explanations & Adult & 96 & 33 & 65 \\
& 4 & 61 & $39(35)^{\mathrm{d}}$ & $50(48)^{\mathrm{d}}$ \\
& 5 & 74 & $44(45)^{\mathrm{d}}$ & $59(59)^{\mathrm{d}}$ \\
& 7 & 88 & $58(43)^{\mathrm{d}}$ & $73(65)^{\mathrm{d}}$ \\
& Adult & 96 & $74(63)^{\mathrm{d}}$ & $85(79)^{\mathrm{d}}$ \\
\hline
\end{tabular}

a Explanations for target characters' emotions in Study 2.

b Explanations for secondary characters' emotions in Study 2.

c Percentage combined across character type; out of eight trials per participant.

d Percentage of internal-psychological explanations for just negative emotions is shown in parentheses.

frequency with which children and adults mention internal-psychological causes as the explanation for current emotions - not just thinking or remembering but also references to a person's desires, beliefs, attitudes about, or empathy towards another person or situation?

To examine this possibility, target character and secondary character explanations were assessed for whether they either (1) contained an explicit reference to mind or emotion (e.g., know, believe, want, think, like, hate), as in, "He's mad because he didn't want her to play"; or (2) linked a person's current emotion to empathy for another character, such as, "She's sad because she feels sorry for her friend." Participants received a score from 0 to 4 for the target character and 0 to 4 for the secondary character totaling the number of story trials for which they provided such internalpsychological explanations. Interrater reliability based on $50 \%$ of the transcripts at each age group was $97 \%$.

Again, Table 6 shows the primary results. An Age (4) $\times$ Character (2) repeated measures ANOVA resulted in main effects for age and character, $p s \leq .001$. Most importantly, both children and adults were more likely to connect emotions to internal, psychological causes when they were knowledgeable $(M=80 \%$ explanations) versus ignorant about a person's past $(M=54 \%)$. Without information about the past, children and adults more often explained emotions as caused by external events, rather than the character's appraisal, desires, or beliefs about those events (e.g., "She's happy because the clown gave everyone a balloon").

The concern in this analysis, however, was that internal-psychological explanations may have been lower for secondary characters, in part, because of emotion valence. Whereas participants had to explain the cause of only negative emotions for the target character, they had to reason about both negative and positive emotions for the secondary character. An additional Age (4) $\times$ Character (2) repeated measures ANOVA was therefore conducted for negative emotions only. These data are shown in parentheses in Table 6. Confirming the initial findings, there was a large effect for character, $p \leq .001$. Indeed, children and adults were nearly twice as likely to attribute characters' negative affect to internal-psychological causes when they were knowledgeable $(M=80 \%$ explanations) versus ignorant $(M=46 \%)$ about a person's past. This was true for negative emotions that matched the current situation (Ms $=69 \%$ versus $24 \%$ for target versus secondary characters), and for negative emotions that mismatched the present circumstances $(M s=91 \%$ versus $69 \%$ for target versus secondary characters), $p \mathrm{~s} \leq .05$.

\section{Discussion}

As in Study 1, 4- and 5-year-olds demonstrated greater knowledge about connections between present emotions and the past and between thinking and feeling in situations where target characters' negative emotions mismatched versus matched the current situation. Four-year-olds were twice as likely to suggest a prior event ( $M=73 \%$ explanations), thinking $(M=$ $55 \%)$, or cognitive cuing $(M=50 \%)$ to explain a target character's anger or sadness in a currently positive situation than his or her angry or sad feelings in a currently negative situation. Similarly, 5-year-olds also provided more prior experience, thinking, and cognitive cuing explanations for mismatched versus matched negative emotions $(M s=75 \%$ versus $60 \%$, $73 \%$ versus $53 \%$, and $70 \%$ versus $35 \%$ for prior ex- 
perience, thinking, and cognitive cuing explanations respectively).

Additionally, Study 2 included 6- and 7-year-olds not tested in Study 1. These older children demonstrated a pervasive, extended understanding of mind and emotion-one that did not differ significantly from that of adults. Early grade-school children consistently offered prior experience, thinking, and cognitive cuing explanations for all target characters' negative emotions, regardless of whether these feelings matched $(M s=75 \%$ or better $)$ or mismatched $(M s=80 \%$ or better) present objective circumstances. In comparison with younger children, the frequency of such explanations for matched emotions is most striking. That is, even when a person's anger or sadness could be attributed to the present situation alone, 6- and 7year-olds, like adults, coordinated present and past into multitemporal situational and mental explanations, such as, "Mark's mad because the girl knocked down his tower AND because she makes him think about when his teddy bear was stolen."

The comparison of emotion explanations for target characters (whose past was known) versus secondary characters (whose past was unknown) was especially revealing. These analyses showed that a biographical framework encourages children, like adults, to explain people's emotions in terms of their personal life histories, as well as their desires, beliefs, or thoughts about current or past situations. Indeed, 4-, 5-, and 7 -year-olds and adults were three times as likely to suggest prior experience for target characters' negative emotions ( $M=76 \%$ explanations) than for secondary characters' mad or sad emotions $(M=24 \%)$ and nearly twice as likely to provide internal-psychological explanations for target characters' negative emotions $(M=80 \%$ explanations) than for secondary characters' negative emotions $(M=47 \%)$. When a person's relevant past history was unknown, emotions were more often explained in relation to recent events (e.g., "He's sad because he fell down"; "He's happy because the car did a trick"). Consistent with these findings, prior studies have shown that adults attribute people's behavior to more complex psychological and historical influences when they know versus don't know about their past history (see Bem, 1972; Jones, 1990; Jones \& Nisbett, 1971; Kelley, 1967, 1971). The current research not only extends this reasoning to emotions but further demonstrates such social sensitivity in 4-year-olds.

Finally, the noneffect of person-person fit in Study 2 is of importance. Children and adults attributed the target characters' negative emotions to prior experience, thinking, and cognitive cuing as frequently when the secondary character felt the same negative emotion as when the secondary character felt happy instead. That is, the juxtaposition of feelings between the two characters did not help spotlight the peculiarity of the target characters' emotional response. It is not, however, that children and adults neglected to consider the other person in their emotion explanations. For example, $15 \%$ of 4 -year-olds, $25 \%$ of 5 -yearolds, $30 \%$ of 7 -year-olds, and $40 \%$ of adults explained that a person's emotions resulted from empathy (e.g., "She's sad because she feels sorry for her friend"), with the majority of participants $(\geq 69 \%)$ suggesting at least once that a character's emotions were caused by knowledge, ignorance, or lack of shared experience in the friend's past trauma (e.g., "He's happy because he doesn't know about the broken bicycle").

\section{GENERAL DISCUSSION}

In contrast to voluminous descriptions of young children's knowledge about mental states, such as beliefs, desires, and intentions (see Lewis \& Mitchell, 1994; Perner, 1991; Wellman, 1990), much less is known about their understanding of active thinking (see Flavell et al., 1995). Even more neglected, but perhaps more important, are investigations of the coherence of children's mental state understandings. In particular, how do young children sum together a person's experiences and mental states to create a sense of that person's life history - an individual, extended through time; a person whose current thoughts, feelings, and actions are continually influenced by his or her past? Our findings suggest a provocative developmental account of these understandings by revealing the situations where young children first demonstrate knowledge about past-present connections and thinking and the situations where they do not. Most centrally, our data suggest that preschoolers' explanations for negative emotions, particularly those that mismatch, or are discordant with, current situations, provide an early breeding ground for developing a coherent mental and historical understanding of people.

\section{Early Achievements}

Recognizing continuity between past experience and current life is a critical feature of mature psychological reasoning. This awareness enables the development of an autobiographical sense of self, or the ability to appreciate the self as essentially "the same person" despite physical changes or the passage of time (see Povinelli \& Simon, 1998). More importantly, linkages between past and present provide an alternative explanatory framework for making sense of our own actions and emotions as well as those of 
the people around us. That is, throughout our everyday lives, we often predict or explain people's reactions not only in relation to present objective circumstances but also in relation to their past actions and experiences (Jones, 1990; Kelley, 1967, 1971; Ross \& Nisbett, 1991).

The current data show that most 3-year-olds recognize connections between people's current situations and their past history, at least at times. Across both studies, historical reasoning was particularly common when children were asked to explain why a character, who had experienced a negative event in the past (Anne's doll is broken by a clown), later started to feel upset in a currently positive situation (the clown gives Anne a balloon). In their explanations for unusual anger or sadness, most 3-, 4-, and 5-year-olds suggested that characters' feelings were caused by the distal past (e.g., "Anne's sad because that's the clown that broke her doll before"). Moreover, 3-, 4-, and 5-year-olds consistently predicted that a person who did not share in the past event would have a different affective reaction to the current situation (e.g., Anne's friend will feel happy to get the balloon). These explanations and predictions show that not only can young children link a person's present and past experiences, but they further understand that prior experience can have a lasting effect. Indeed, only $4 \%$ of preschoolers never referred to a person's past in their explanations for emotions or actions.

Still, preschoolers went beyond just making sense of characters' present feelings in terms of their distinctive past events. They used mental activity to bridge together characters' past and present experiences. Again, these early insights were especially centered around mismatched negative emotions. Half of the 3-year-olds and most 4- and 5-year-olds explained that a character's atypical anger or sadness was not just connected to prior experience but rather was caused by remembering that past negative incident (e.g., "Anne's sad because she's remembering her broken doll"). Moreover, many preschoolers (a minority of 3-year-olds and most 5-year-olds) provided complete cognitive cuing explanations, which showed that they not only understood when and what a person was thinking about but also why (e.g., "Mary's sad because the dog makes her think about her bunny"). Thus, during the preschool years children increasingly appreciate that past experiences are influential when we remember them-through actively thinking and focusing on them. Indeed, young children recognize that mental recollections are sometimes so powerful that they can induce emotions incommensurate with current reality, such as feeling mad in a conventionally happy situation because of angry thoughts.

\section{Later Developments}

At the same time that young children revealed strong awareness of historical and mental causes of mismatched negative emotions, they often ignored people's prior history in their explanations for other reactions and chose instead to focus on antecedents in the present scene. For example, only a minority of preschoolers attributed people's current happiness, even happy feelings during negative events (e.g., happy after spilling a milkshake) to thinking about the past. Moreover, when negative feelings matched current events (e.g., Anne's mad when the clown soaks her with a water balloon), 3-year-olds never and 4- and 5-year-olds inconsistently suggested that characters might be remembering a prior negative incident. Finally, preschoolers, especially 3- and 4-yearolds, infrequently explained characters' current behaviors in terms of thinking about the past. Indeed, outside the context of mismatched negative emotions, 3- to 5-year-olds typically centered on salient events in the here and now, providing sensible and legitimate present-focused explanations such as, "He's happy because he'll get another milkshake," or "Anne's mad because she's wet."

When combined with data from 6- and 7-year-olds, a more complete developmental picture emerges. First, explanations by these older children and by adults revealed that mismatched negative emotions are significant for early development. In contrast to preschoolers, 6- and 7-year-olds and adults explained nearly all negative emotions in terms of being reminded about a past negative event, when such biographical information was available for consideration. Even when anger or sadness matched present objective events, children as young as 6 years largely provided mental explanations: “Brian's sad because he fell down and because the car reminds him about his broken bicycle." Second, the inclusion of older participants showed that biographical information is influential across age. That is, without knowledge about prior experience (secondary characters), children and adults rarely provided past-related causes, nor did they consistently suggest internal-psychological influences of emotions, such as a person's beliefs or desires. Therefore, mismatched negative emotions in conjunction with past history information provide an important entryway for recognizing the influence of life history and ongoing thoughts. These early insights then quickly expand into more pervasive, comprehensive understandings. 


\section{Conclusions}

Aside from illuminating the strengths and weaknesses of children's knowledge about past events and thoughts, preschoolers' differential performance on different story types provides a critical methodological control. For example, it is possible that the extended procedures used in this research to elicit explanations simply provoked indiscriminate, talkative answers. Or it could be argued that the tasks unnaturally prompted children to consider past events. That is, young children may have attributed emotions to thinking about the past because relevant biographical information was blatantly presented. Moreover, it is possible that participants themselves were "cued" to remember the past events and then merely reported their own thoughts.

Several findings refute such concerns. For example, children made different predictions for (Study 1) and provided different explanations for (Study 2) the emotions of secondary characters versus target characters, even though both people were in the same current situation. Even more, the very fact that preschoolers often failed to consider prior experience in their explanations for target characters' positive emotions, matched negative emotions, and behaviors is methodologically important. That is, despite parallel information provided across story types (specific past experiences and present cues), only in the particular case of mismatched negative emotions did preschoolers consistently look to the past to explain current emotions. Take, for example, mismatched positive emotions. Many preschoolers were baffled by unusual positive emotions to the point that one 4-year-old suggested that such emotions cannot be explainedeven if one were a "professional, adult, mystery spy"! Therefore, the sophistication of preschoolers' explanations for mismatched negative emotions cannot be reduced to a methodological artifact. Rather, young children explain unusual negative emotions in terms of past events and thoughts because these emotions, events, and thoughts are meaningfully connected in their minds.

Differences in young children's explanations for emotions across different situations further reconcile conflicting evidence about how to characterize young children's understanding about interconnections between past events, thinking, and emotions. The current findings do not demonstrate that preschoolers have general early competence in reasoning about life history, mind, and emotion. Consistent with prior research, the present results affirm that young children's understanding about thinking (see Flavell et al., 1993, 1995), the influence of prior experience (see Gnepp 1983; Gnepp, Klayman, \& Trabasso, 1982; Harris, 1989), and the connection between thinking and emo- tion (see Altshuler \& Ruble, 1989; Harris, 1989; Harris \& Lipian, 1989) is limited in comparison with older children and adults. Uniquely, however, the data from this current research also reveal that young children's minimal understanding about historical-mental connections in some situations coexists with sophisticated knowledge in other situations. That is, when story scenarios combined negative affect, incongruity between emotion and situation, and past history information, 3- to 5-year-olds demonstrated early, coherent knowledge about people in historical and mental terms. Presumably, this triad of features is so compelling because it matches young children's early concerns, experiences, and nascent understandings.

This speculation leads to an important remaining question: Why are mismatched negative emotions and past history information important in the development of children's initial insights about people in terms of their distinctive pasts and their thoughts? That is, how can we account for the striking disparity in children's ability to recognize thinking and pastpresent linkages in different contexts? Research on adult social understanding and young children's conversations yield informative clues.

In our day-to-day interactions, humans perceive people's behaviors and emotions as caused by something - whether by situations, personality traits, motivation, thoughts, desires, and so on (Heider, 1944, 1958). Because we believe that actions or emotions have a source, we try to figure out why they happened (Bem, 1972; Kelley, 1967, 1971). Several studies have shown that adults are more compelled to discover the reasons for negative or unexpected outcomes than to explain positive or expected events (see Weiner, 1985). This search for explanation is not peculiar to adults. Starting around age 2, children begin to use causal expressions in their speech to explain the actions or emotions of themselves and other people (Bartsch \& Wellman, 1995; Bloom \& Capatides, 1987; Dunn, Bretherton, \& Munn, 1987; Dunn \& Brown, 1991; Hood \& Bloom, 1979; Wellman, Hickling, \& Schult, 1997). During the preschool years, explanations for people's emotions, especially their negative feelings, become a dominant focus of these conversations (Brown, 1995; Dunn \& Brown, 1993; Hudson, 1991; Lagattuta, 1999; Miller \& Sperry, 1988). Children's early interest in negative emotions is evident not only in their speech but also in their empathetic actions toward people in distress (Zahn-Waxler, RadkeYarrow, Wagner, \& Chapman, 1992).

This focus on negative emotions arguably encourages children to develop earlier, more sophisticated discoveries about their causes in comparison with other affective states (e.g., happiness) or behaviors. 
This seems particularly true when a person's negative emotions are unusual for a situation. Because simple situation-based explanations do not suffice, children are forced to consider alternative, person-specific mental and historical influences. In their attempts to explain these salient and naturally occurring events, children acquire increasingly complex and coherent understandings about minds and emotions and how they influence a person's life in individual, historically connected ways. Indeed, preschoolers' common practice of reminiscing with family members about past events and emotions, particularly negative ones (Dunn et al., 1987; Dunn \& Brown, 1991, 1993; Fivush, 1991; Hudson, 1990; Kuebli \& Fivush, 1992; Miller \& Sperry, 1988; Reese, Haden, \& Fivush, 1993), may provide them with the very model for recognizing these important connections. That is, when remembering and talking about past negative events, children may reexperience the same negative affect or notice such emotion changes in others: feelings not caused by the present situation but by thinking about the past.

If this account is correct then it inspires further research. For example, we have shown that young children differentially use past history information to explain different kinds of emotions and behaviors. An important question thus becomes whether and when children seek this kind of information in their everyday interactions. As Baldwin and Moses (1996) aptly argue, there is a big difference between being a "consumer" versus a "seeker" of social knowledge. Thus, how often do children keep track of the personal experiences of family members and friends? How frequently do they use such historical explanations for emotions? Relatedly, the current findings reveal that young children are more knowledgeable about historical-mental causes of negative emotions in comparison with positive emotions. Thus, how does emotion valence affect young children's "seeking" of knowledge or explanation? For example, do young children differentially seek and provide information about the sources of their own and other people's negative emotions in contrast to positive emotions? Systematic investigations of the specific kinds of causal explanations young children use and the questions they ask about past and present emotions would reveal more clearly how they develop and implement a coherent understanding of life history, mind, and emotion in their day-to-day understanding of self and others.

\section{ACKNOWLEDGMENTS}

This research was supported by fellowships from the National Science Foundation and from the Regents of the University of Michigan to K. H. Lagattuta and by
NICHD grant HD 22149 to H. M. Wellman. The authors would like to thank the staff, parents, and children from the schools who participated in the studies. They would also like to thank Cheryl Kartub Ahrens for her invaluable assistance in data collection, transcribing, and coding.

\section{ADDRESSES AND AFFILIATIONS}

Corresponding author: Kristin Hansen Lagattuta, Developmental Psychology, University of Michigan, 525 East University, Ann Arbor, MI 48109-1109; e-mail: kehansen@umich.edu. Henry M. Wellman is also at the University of Michigan at Ann Arbor.

\section{REFERENCES}

Abramson, L. Y., Seligman, M. E. P., \& Teasdale, J. D. (1978). Learned helplessness in humans: Critique and reformulation. Journal of Abnormal Psychology, 87, 49-74.

Altshuler, J. L., \& Ruble, D. N. (1989). Developmental changes in children's awareness of strategies for coping with uncontrollable stress. Child Development, 60, 1337-1349.

Baldwin, D. A., \& Moses, L. J. (1996). The ontogeny of social information gathering. Child Development, 67, 1915-1939.

Band, E. B., \& Weisz, J. R. (1988). How to feel better when it feels bad: Children's perspectives on coping with everyday stress. Developmental Psychology, 24(2), 247-253.

Banerjee, M. (1993). Preschoolers' understanding of emotion: Appearance-reality, display rules, and regulation strategies (Doctoral dissertation, University of Michigan, 1993). Dissertation Abstracts International, 53, 6003.

Bartsch, K., \& Wellman, H. (1995). Children talk about the mind. Oxford, U.K.: Oxford University Press.

Beck, A. T. (1976). Cognitive therapy and emotional disorders. New York: International Universities Press.

Bem, D. J. (1972). Self-perception theory. In L. Berkowitz (Ed.), Advances in experimental and social psychology (Vol. 6). New York: Academic Press.

Bloom, L., \& Capatides, J. B. (1987). Sources of meaning in the acquisition of complex syntax: The sample case of causality. Journal of Experimental Child Psychology, 43, 112-128.

Borke, H. (1971). Interpersonal perception of young children: Egocentrism or empathy? Developmental Psychol$o g y, 5,263-269$.

Brown, J. R. (1995). What happened?: Emotional experience and children's early talk about the past. Unpublished manuscript.

Butler, R. (1990). The effects of mastery and competitive conditions on self-assessment at different ages. Child Development, 61, 201-210.

Campos, J. J., \& Sternberg, C. R. (1981). Perception, appraisal, and emotion: The onset of social referencing. In M. E. Lamb \& L. R. Sherrod (Eds.), Infant social cognition: Empirical and theoretical considerations (pp. 273-314). Hillsdale, NJ: Erlbaum.

Darley, J. M., \& Latane, B. (1968). Bystander intervention in 
emergencies: Diffusion of responsibility. Journal of Personality and Social Psychology, 8, 377-383.

Dunn, J., Bretherton, I., \& Munn, P. (1987). Conversations about feelings between mothers and their young children. Developmental Psychology, 23, 132-139.

Dunn, J., \& Brown, J. (1991). Relationships, talk about feelings, and the development of affect regulation in early childhood. In J. Garber \& K. A. Dodge (Eds.), The development of emotion regulation and disregulation (pp. 89108). Cambridge, U.K.: Cambridge University Press.

Dunn, J., \& Brown, J. (1993). Early conversations about causality: Content, pragmatics and developmental change. British Journal of Developmental Psychology, 11, 107-123.

Estes, D. (1998). Young children's awareness of their mental activity: The case of mental rotation. Child Development, $69,1345-1360$.

Feinman, S., \& Lewis, M. (1983). Social referencing at 10 months: A second order effect on infants' responses to strangers. Child Development, 54, 878-887.

Fivush, R. (1991). Gender and emotion in mother-child conversations about the past. Journal of Narrative $\mathcal{E}$ Life History, 1, 325-341.

Flavell, J. H., Green, F. L., \& Flavell, E. R. (1993). Children's understanding of the stream of consciousness. Child Development, 64, 387-398.

Flavell, J. H., Green, F. L., \& Flavell, E. R. (1995). Young children's knowledge about thinking. Monographs of the Society for Research in Child Development, 60(1, Serial No. 243).

Flavell, J. H., Green, F. L., \& Flavell, E. R. (1998). The mind has a mind of its own: Developing knowledge about mental uncontrollability. Cognitive Development, 13, 127-138.

Gnepp, J. (1983). Children's social sensitivity: Inferring emotions from conflicting cues. Developmental Psychology, 19, 805-814.

Gnepp, J. (1989). Children's use of personal information to understand other people's feelings. In C. Saarni \& P. L. Harris (Eds.), Children's understanding of emotion (pp. 151-177). New York: Plenum Press.

Gnepp, J., \& Gould, M. E. (1985). The development of personalized inferences: Understanding of other people's emotional reactions in light of their prior experiences. Child Development, 56, 1455-1464.

Gnepp, J., Klayman, J., \& Trabasso, T. (1982). A hierarchy of information sources for inferring emotional reactions. Journal of Experimental Child Psychology, 33, 111-123.

Gove, F. L., \& Keating, D. P. (1979). Empathetic role-taking precursors. Developmental Psychology, 15, 594-600.

Harris, P. L. (1989). Children and emotion: The development of psychological understanding. Oxford, U.K.: Basil Blackwell.

Harris, P. L., Guz, G. R., Lipian, M. S., \& Man-Shu, Z. (1985). Insight into the time course of emotion among Western and Chinese children. Child Development, 56, 972-988.

Harris, P. L., Johnson, C. N., Hutton, D., Andrews, G., \& Cooke, T. (1989). Young children's theory of mind and emotion. Cognition and Emotion, 3, 379-400.

Harris, P. L., \& Lipian, M. S. (1989). Understanding emotion and experiencing emotion. In C. Saarni \& P. L. Harris (Eds.), Children's understanding of emotions (pp. 241-258). New York: Cambridge University Press.
Heider, F. (1944). Social perception and phenomenological causality. Psychological Review, 51, 258-374.

Heider, F. (1958). The psychology of interpersonal relations. New York: Wiley.

Hood, L., \& Bloom, L. (1979). What, when and how about why: A longitudinal study of early expression of causality. Monographs of the Society for Research in Child Development, 44(6, Serial No. 181).

Hudson, J. (1990). The emergence of autobiographic memory in mother-child conversation. In R. Fivush \& J. A. Hudson (Eds.), Knowing and remembering in young children. New York: Cambridge University Press.

Hudson, J. (1991). Learning to reminisce: A case study. Journal of Narrative and Life History, 1, 295-324.

Jones, E. E. (1990). Interpersonal perception. New York: Freeman.

Jones, E. E., \& Nisbett, R. E. (1971). The actor and the observer: Divergent perceptions of the causes of behavior. In E. E. Jones, D. E. Kanouse, H. H. Kelley, R. E. Nisbett, S. Valins, \& B. Weiner (Eds.), Perceiving the causes of behavior. Morristown, NJ: General Learning Press.

Kelley, H. H. (1967). Attribution theory in social psychology. In D. Levine (Ed.), Nebraska symposium on motivation (Vol. 15). Lincoln: University of Nebraska Press.

Kelley, H. H. (1971). Causal schemata and the attribution process. In E. E. Jones, D. E. Kanouse, H. H. Kelley, R. E. Nisbett, S. Valins, \& B. Weiner (Eds.), Perceiving the causes of behavior. Morristown, NJ: General Learning Press.

Kuebli, J., \& Fivush, R. (1992). Gender differences in parentchild conversations about past emotions. Sex Roles, 27, 683-698.

Lagattuta, K. H. (1999). The development of young children's understanding of the causes of emotions: Experimental and natural language studies. Unpublished doctoral dissertation, University of Michigan.

Lagattuta, K. H., Wellman, H. M., \& Flavell, J. H. (1997). Preschoolers' understanding of the link between thinking and feeling: Cognitive cuing and emotional change. Child Development, 68, 1081-1104.

Latane, B., \& Darley, J. M. (1968). Group inhibition of bystander intervention in emergencies. Journal of Personality and Social Psychology, 10, 215-221.

Lewis, C., \& Mitchell, P. (Eds.). (1994). Origins of an understanding of mind. Hillsdale, NJ: Erlbaum.

Liwag, M. D., \& Stein, N. L. (1995). Children's memory for emotional events: The importance of emotion-related retrieval cues. Journal of Experimental Child Psychology, 60, $2-31$.

Miller, P. J., \& Sperry, L. L. (1988). Early talk about the past: The origins of conversational stories of personal experience. Journal of Child Language, 15, 293-315.

Mumme, D. L., Fernald, A., \& Herrera, C. (1996). Infants' responses to facial and vocal emotional signals in a social referencing paradigm. Child Development, 67, 3219-3237.

Nolen-Hoeksema, S. (1991). Responses to depression and their effects on the duration of depressive episodes. Journal of Abnormal Psychology, 100(4), 569-582.

Perner, J. (1991). Understanding the representational mind. Boston, MA: MIT. 
Povinelli, D. J., \& Simon, B. B. (1998). Young children's understanding of briefly versus extremely delayed images of the self: Emergence of the autobiographical stance. Developmental Psychology, 34, 188-194.

Reese, E., Haden, C. A., \& Fivush, R. (1993). Mother-child conversations about the past: Relationships of style and memory over time. Cognitive Development, 8, 403-430.

Ross, L., \& Nisbett, R. E. (1991). The person and the situation: Perspectives of social psychology. New York: McGraw-Hill.

Ruble, D. N., Boggiano, A. K., Feldman, N. S., \& Loebl, J. H. (1980). Developmental analysis of the role of social comparison in self-evaluation. Developmental Psychology, 16, 105-115.

Russell, J. A. (1990). The preschooler's understanding of the causes and consequences of emotion. Child Development, 61, 1872-1881.

Sacco, W. P., \& Beck, A. T. (1985). Cognitive therapy of depression. In E. E. Beckham \& W. R. Leber (Eds.), Handbook of depression (pp. 3-38). Homewood, IL: Dorsey Press.

Schachter, S., \& Singer, J. E. (1962). Cognitive, social, and physiological determinants of emotional state. Psychological Review, 69, 379-399.

Stein, N. L., \& Levine, L. (1987). Thinking about feelings: The development and organization of emotional knowledge. In R. E. Snow \& M. Farr (Eds.), Aptitude, learning, and instruction: Vol. 3. Cognition, conation, and affect (pp. 165-198). Hillsdale, NJ: Erlbaum.
Stein, N. L., \& Levine, L. (1989). The causal organization of emotional knowledge: A developmental study. Cognition and Emotion, 3, 343-378.

Stein, N. L., \& Trabasso, T. (1989). Children's understanding of changing emotion states. In C. Saarni \& P. Harris (Eds.), The development of emotional understanding (pp. 5077). New York: Cambridge University Press.

Stipek, D., Recchia, S., \& McClintic, S. (1992). Self-evaluation in young children. Monographs of the Society for Research in Child Development, 57(1, Serial No. 226).

Weiner, B. (1985). "Spontaneous" causal thinking. Psychological Bulletin, 97, 74-84.

Wellman, H. M. (1990). The child's theory of mind. Cambridge, MA: MIT Press.

Wellman, H. M., \& Banerjee, M. (1991). Mind and emotion: Children's understanding of the emotional consequences of beliefs and desires. British Journal of Developmental Psychology, 2, 191-214.

Wellman, H. M., Hickling, A. K., \& Schult, C. A. (1997). Young children's explanations: Psychological, physical, and biological reasoning. In H. M. Wellman \& K. Inagaki (Eds.), The emergency of core domains of thought: Physical, psychological, and biological thinking. San Francisco: Jossey Bass.

Zahn-Waxler, C., Radke-Yarrow, M., Wagner, E., \& Chapman, M. (1992). Development of concern for others. Developmental Psychology, 28, 126-136. 